node-positive disease. ${ }^{[2]}$ With the reduced morbidity and mortality rates of Whipple's pancreatico-duodenectomy in high-volume centers, it should be the obvious procedure of choice for these tumors.

H owever, there are situations where a pancreaticoduodenectomy might not be technically possible, as highlighted in the article by $\mathrm{H}$ wang $\&$ al., ${ }^{[3]}$ where they describe a very rare case of carcinoid tumor of ampulla of Vater associated with diffuse cavernous transformation of the portal vein, secondary to main portal vein obliteration of unknown origin. They had to perform a retrodudenal resection of the ampullary carcinoid tumor, followed by reconstruction using Roux-en-Y pancreaticojejunostomy and choledochojejunostomy.

Few other limited resection procedures have been described in literature for these tumors. The least aggressive of these is transduodenal ampullectomy, ${ }^{[4]}$ which requires in stu reconstruction of the resected duct stumps to the duodenal wall. While the most aggressive procedure described, is a major or total resection of the duodenum, where a jejunal Roux limb is used for anastomosis to the stomach and for reconstruction of the distal CBD and pancreatic duct openings. ${ }^{[5]}$

In conclusion, due to the technical complexity of these procedures along with the added risk of insufficient resection margins, these limited resection procedures should be considered a choice only in a small number of highly selected patients.

Sharma R Department of Surgical Oncology, IRCH, All India Institute of Medical Sciences, New Delhi, India

Correspondance to: Dr. Sharma Rajeev E-mail: rajeevsharma28@yahoo.co.in

\section{Limited resection procedures for carcinoid of ampulla of Vater}

\section{Sir,}

I read with great interest the article by Rohan \& al., ${ }^{[1]}$ where they have described the management of a rare case of carcinoid of ampulla of Vater. Given the high metastatic potential of these tumors, local resection definitely has a high propensity to leave behind

\section{References}

1. Tankshali RA, Patel JJ, Narendra H, Rohan VS, Abhinandan H. Carcinoid of ampulla of Vater. Indian J Cancer 2007;44:90-2.

2. Ricci JL. Carcinoid of the ampulla of Vater, Local resection or pancreaticoduodenectomy. Cancer 1993;71:686-90.

3. Hwang S, Moon KM, Park JI, Kim MH, Lee SG. Retroduodenal resection of ampullary carcinoid tumor in a patient with cavernous transformation of the portal vein. J Gastrointest Surg 2007; 11:1322-7.

4. Dittrick GW, Mallat DB, Lamont JP. Management of ampullary lesions. Curr Treat Opt Gastroenterol 2006;9:371-6.

5. Mackey R, Walsh RM, Chung R, Brown N, Smith A, Church J, et al. Pancreas-sparing duodenectomy is effective management for familial adenomatous polyposis. J Gastrointest Surg 2005;9: 1088-93. 